\title{
ANGIOCARDIOGRAPHY IN HEART DISEASE IN CHILDREN
}

\author{
BY \\ RODOLFO O. KREUTZER, JUAN A. CAPRILE, AND FREDERIK M. WESSELS \\ From the Cardiac Clinic, Children's Hospital, Buenos Aires, Argentina
}

Received October 12, 1949

We present here some of our experience of angiocardiography; it deals exclusively with children and infants as a result of our working in a children's hospital.*

When a careful clinical examination, electrocardiograms, $X$ rays, and the simple laboratory tests do not make the diagnosis certain, we have two principal procedures: heart catheterization with study of the pressures and gas content from samples obtained in different chambers of the heart, and in addition, angiocardiography. Although the first procedure is of great value, it is very difficult to perform on young children because of their small veins and lack of co-operation. On the contrary, angiocardiography is simple and harmless as far as our experience shows.

Although the extensive and careful study Taussig made of the clinical and radiological picture of the different congenital heart malformations means a very great aid to diagnosis, we still believe that, especially in infants, angiocardiography can be a great help. At this early age diagnosis is difficult because the heart has not acquired its typical form and the physical and electrocardiographic signs are not yet clearly evident. It is also at this stage that the angiocardiograms are clearest as is illustrated by some of the pictures shown here. Therefore, we consider angiocardiography essential in diagnosing congenital heart diseases in infants, and certainly of great help even if not essential in older children.

\section{HISTORICAL}

The first attempt was made by Forssmann in 1929; after introducing a rubber catheter as far as the right auricle, by way of a vein in his own arm, he made a trial at visualization by injecting some opaque material and taking $\mathrm{X}$ rays.

After this, Moniz, Carvalho, and Lima in 1932; Conte and Costa in 1933; Ravina, Sourire, and Benzaquen in 1932; and Ameuille et al. in 1936 made several attempts to visualize the right cavities of the heart and mainly the pulmonary arteries in animals and men, all more or less following Forssmann's technique. In 1933, Reboult and Racine visualized very distinctly in dogs the right and left cavities of the heart, the aorta, and the coronary arteries, by introducing a needle directly into the heart and injecting a radio-opaque substance.

In 1937, Castellanos, Pereiras, and Garcia from Havana, Cuba, obtained for the first time a good visualization of the right side of the heart, pulmonary artery, and its branches in living children, after injecting perabrodil 35 per cent directly into a vein of the arm. They were the first to use the term " angiocardiography" which has become classical, and they pointed out the simplicity of the method and its value in the diagnosis of congenital heart disease.

Shortly afterwards, Robb and Steinberg, 1938 and 1939, in New York, used for the first time 70 per cent diodrast and a mechanical cassette changer, thus obtaining good visualization of the left side and aorta as well as the right. They used this procedure successfully on adults, which Castellanos, Pereiras, and Garcia had been unable to do, because of the lack of an adequate contrast

\footnotetext{
* When one of the authors (R. K.) was in England recently, the editor was interested seeing his clear and striking angiocardiograms and suggested that he might submit a paper on the subject for publication in the B.H.J. (M. C.). 
medium. They emphasized the value of this method in studying the topography of the heart and in the differential diagnosis of mediastinal tumours and various cardiac diseases.

Stewart, Breimer, and Maier were the first to take a motion picture of the fluoroscopic image, and others took photographs of it, the results not being as clear as ordinary $\mathrm{X}$ rays. Chavez et al., going back to Moniz's method, injected the opaque substance through a catheter, introduced into the jugular vein up to the right auricle, and obtained very clear pictures.

Further work has been done on the subject by many others including Sussman and Grishman, Taylor and MacGovern, Keele, Thoyer-Rozat and Piquet, and Carson and his associates. Dotter and Steinberg (1949) have published their experiences with more than a thousand angiocardiograms taken during the last eleven years.

In our country, Spangenberg et al. (1942) and Kreutzer, Pelliza, and Calisti (1944) made the first publications in this field. Segura et al., Pennington, and Malenchini have also worked in this line.

\section{TECHNIQUe}

No special preparation of the patient is necessary except that he must have had nothing to eat during the previous four hours. As the intracutaneous and intra-ocular sensitization tests are not very accurate, we do not use them. However, in patients with an allergic history, we inject intravenously $2 \mathrm{ml}$. of the iodine compound used and, if there is no reaction five minutes later, we inject the rest.

We have used several different compounds (iodoxil, nosylam, perabrodil, neo-iopax), but the best results were obtained with diodone (official British pharmaceutical name), 75 per cent solution with 51.5 per cent iodine which is sold in our country under the name nitasom and in England as pyelectan. The manufacturers warn against the use of this contrast medium in angiocardiography, saying that it is painful and that when it is injected outside the vein it produces abscesses, but in our experience we have not had such a consequence. The amount to be used varies with the age: $10 \mathrm{ml}$. in the newborn, $12 \mathrm{ml}$. up to 3 months, $15 \mathrm{ml}$. up to 1 year, and from then on we calculate about $1.5 \mathrm{ml}$. per kilo body weight; an average of $20 \mathrm{ml}$. for children up to 3 years, $30 \mathrm{ml}$. up to 6 , and about $60 \mathrm{ml}$. for adults. We consider that less than $1 \mathrm{ml}$. per kilo body weight is insufficient, especially when there is cardiac enlargement.

The syringes we use do not differ from the ordinary except that the hole in the cone must be large. The diameter of the needle used varies with the age of the patient: $10 / 10 \mathrm{~mm}$. in the new born $12 / 10 \mathrm{~mm}$. in the infant, $15 / 10 \mathrm{~mm}$. in children up to 3 years, it being necessary to use at least $20 / 10 \mathrm{~mm}$. when the injection is of $30 \mathrm{ml}$, and $30 / 10 \mathrm{~mm}$. if it is more. The injection is made directly through the skin without exposing the vein, ${ }^{*}$ with local novocaine anæsthesia. We never use a general anæsthetic. Very seldom, even in small infants, have we found it impossible to introduce the needle into a vein, and for this reason we believe the dissection of the vein unnecessary. The injection should be made very rapidly, in less than 1.5 seconds.

The films are taken at a distance of 1 meter with $100 \mathrm{ma}$. in $1 / 10 \mathrm{sec}$., the kilovoltage varying according to the thickness of the thorax, but using about 25 per cent more than the usual for the exposure of the heart. $\dagger$

All the angiocardiograms are taken in the horizontal position on a cassette changer described by one of us (R.K.) in a previous paper, and in the left anterior oblique position (because we consider this the one in which the four cavities of the heart are best seen), unless the previous clinical examination suggests that another would be better. Four films are taken with one second between them, unless we are especially interested in the left side of the heart, and then the last two are somewhat delayed.

Immediately after the injection, a sensation of heat is usually felt as well as palpitation, itching, and frequently a severe headache; vomiting may occur shortly afterwards. Generally, a great thirst follows and even infants take water avidly. All these reactions last only a few minutes. In

* The injection is made by Dr. Juan Marletta.

$\dagger$ The roentgen technique is under the supervision of Dr. Sofio Calisti. 
taking more than 400 angiocardiograms we have lost only one patient, an infant with complete transposition of the great vessels, who died 12 hours after the procedure, with high fever $\left(41^{\circ} \mathrm{C}\right.$.) and convulsions.

\section{Presentation of Material}

We have purposely selected those cases that were substantiated by necropsy or operation. We need not give a detailed description of the normal angiocardiogram as this has already been done by others. We show only two views taken in the left anterior oblique position, because this is the one we ordinarily use.

A normal dextro-angiocardiogram is shown in Fig. 1. The dye is seen in the right humeral and subclavian veins (1); the superior vena cava is already empty; the right cavities are well filled; it is difficult to differentiate the right auricle (2) from the ventricle (3) as they lie on the same level, one directly back of the other; the interventricular septum is straight and is parallel to the spinal column; the main pulmonary artery (4), and the left pulmonary artery (5) are clearly seen, whereas, from the right pulmonary artery (6) only the finer branches are seen.

A normal lavo-angiocardiogram is seen in Fig. 2. After passing through the lungs, the dye fills the left cavities (1); the aorta is well filled (2) and from its arch emerge the following vessels; inominate artery (3) and its two branches, right carotid (4) and right subclavian (5); left carotid (6), and left subclavian (7) from which the vertebral is seen to arise; the descending aorta (8) can be

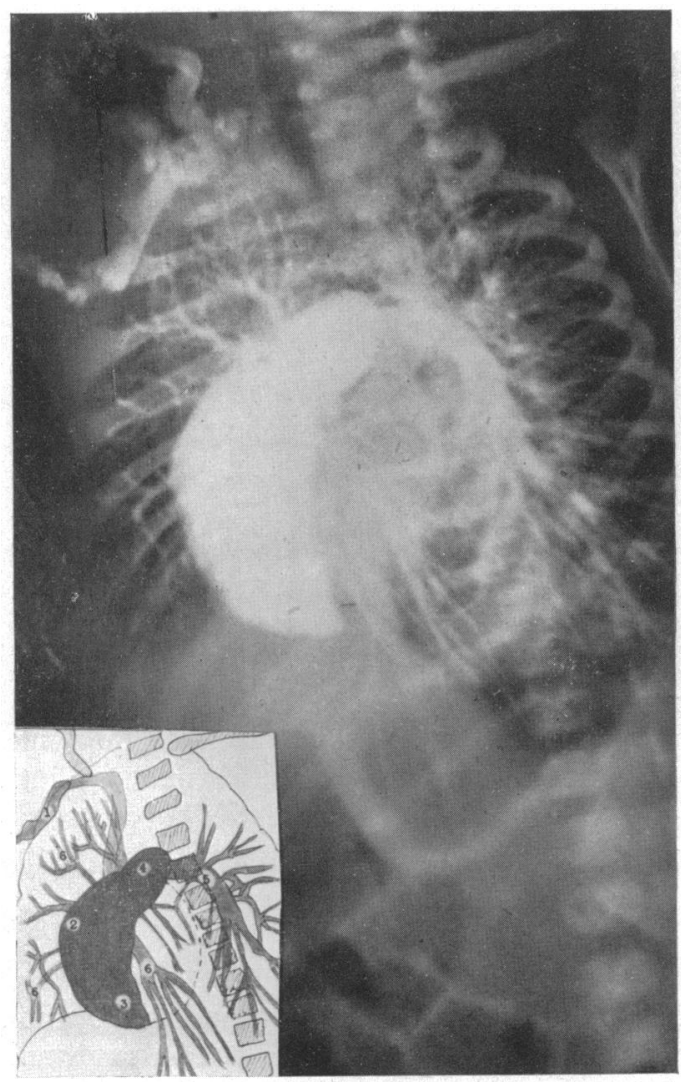

FIG. 1.-Normal dextro-angiocardiogram in left antero-posterior position from infant, aged 5 days. For explanation and figures see text.

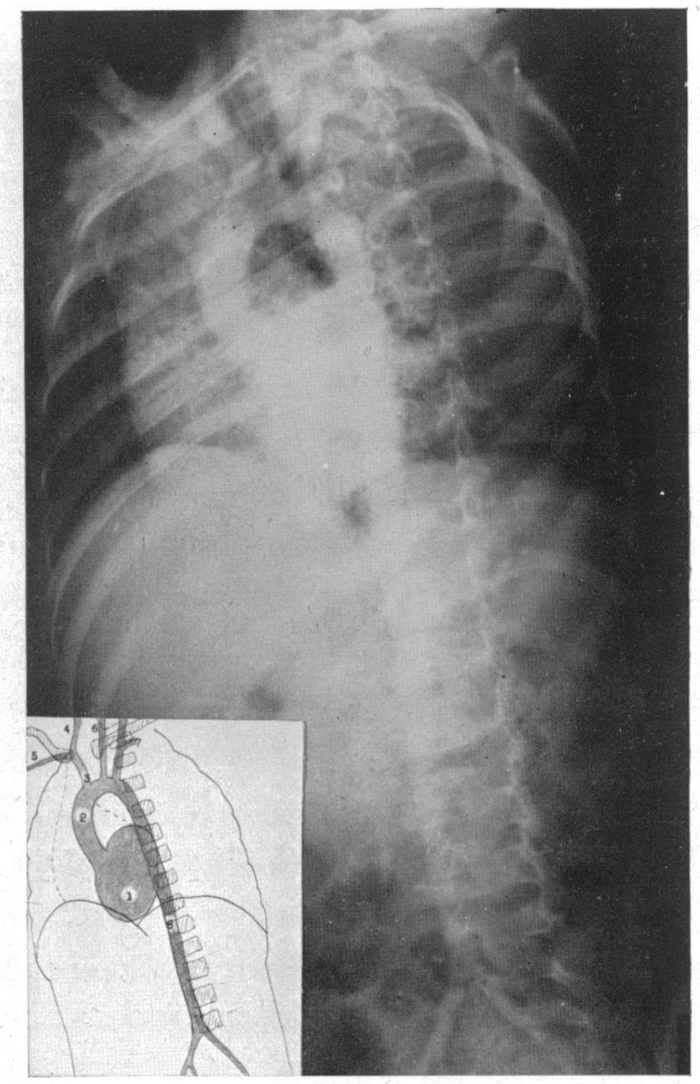

FIG. 2.-Normal lævo-angiocardiogram in left antero-posterior position from a child, aged 3 years (see text). 
clearly distinguished up to its division into left and right iliacs; the aorta is curved in the form of a cane handle sharply bent; the interventricular septum is straight and parallel to the spinal column. In the left anterior oblique position, the anterior border of the ascending aorta does not form, at least in the child, the anterior part of the vascular shadow at the base of the heart. Under the aortic arch is seen the normal clarity of the vascular window.

\section{Atelectasis of the Right Lung}

M.T.C., aged 26 days. Normal until 15 days when fever, dyspnœa, and cyanosis appeared. The child was found to be poorly developed, acutely ill, cyanotic, and gasping for breath; the heart was percussed on the right; the cardiac sounds were faint and no murmurs were heard. Based on the X-ray a diagnosis of dextrocardia and congenital heart disease and bronchial pneumonia was made by the doctor who sent the child to us. Although we suspected atelectasis of the right lung to be the main cause of his distress, basing our belief on the normal electrocardiogram and the displacement of the mediastinum to the right, we made an angiocardiogram which is shown in Fig. 3.

The typical U-shaped contour described by Castellanos et al. (1937) is seen. Superior vena cava (1); right auricle (2); right ventricle (3); main pulmonary artery (4); the right pulmonary artery has a horizontal position closing the upper part of the $U(5)$; the left pulmonary artery (6) helps together with the main pulmonary artery to form the middle segment of the left border of the heart. The interventricular septum is straight and parallel to the spinal column, thus following a different direction from the interventricular groove. In looking at this angiocardiogram we were surprised to find that the heart was in its normal position, which fact was further substantiated by a second X-ray. The patient had had a severe coughing attack while being made ready for the angiocardiogram, which probably helped to clear the bronchi and expand the lungs.

\section{Agenesis of the Right Lung}

M.S., aged 1 month. Dyspnœa and slight cyanosis from birth; large umbilical hernia operated on a few days before. A poorly developed, cyanotic child, breathing rapidly. The apex was thought to be palpated on the right. Electrocardiogram: right axis deviation but not a mirror image in the first lead as would be expected in a dextrocardia. $\mathrm{X}$ ray: the heart on the right side of the chest, the left lung introducing itself into the right hemithorax. After barium, the stomach could be seen on the left; the liver is seen on the right side and is considerably enlarged.

The angiocardiogram (Fig. 4) taken at the same time shows the humeral vein (1); subclavian, superior vena cava, right cavities (2) from which a good sized pulmonary artery emerges, continuing into a voluminous left pulmonary artery. The left ventricle is also filled (3), and the aorta (6) whose arch makes a loop can be seen up to its division into two iliacs. The circulation in the left lung is clearly seen, but on the right no pulmonary artery and no circulation is visible. Therefore, aginesis of the right lung was suspected. An interventricular septal defect, through which the left ventricle and the aorta had filled, was also diagnosed.

The patient died due to the rupture of the umbilical hernia and the autopsy confirmed the clinical diagnosis: agenesis of the right lung, the trachea continuing directly into the left bronchus; interventricular septal defect with the aorta emerging completely from the left ventricle; a big pulmonary artery coming off the right ventricle gave only one branch, the left one, which was even larger than the aorta.

\section{Tetralogy of Fallot and Persistent Ductus Arteriosus}

M.C.P., aged 8 days. Persistent cyanosis from birth with frequent attacks of increased cyanosis and dyspnea, in some of which he lost consciousness. The heart sounds were normal, no murmurs. Electrocardiogram, right axis deviation. Fluoroscopic examination shows an enlarged heart and clear lung fields. As is usual at this age, the form of the heart did not contribute to the diagnosis of the malformation. 


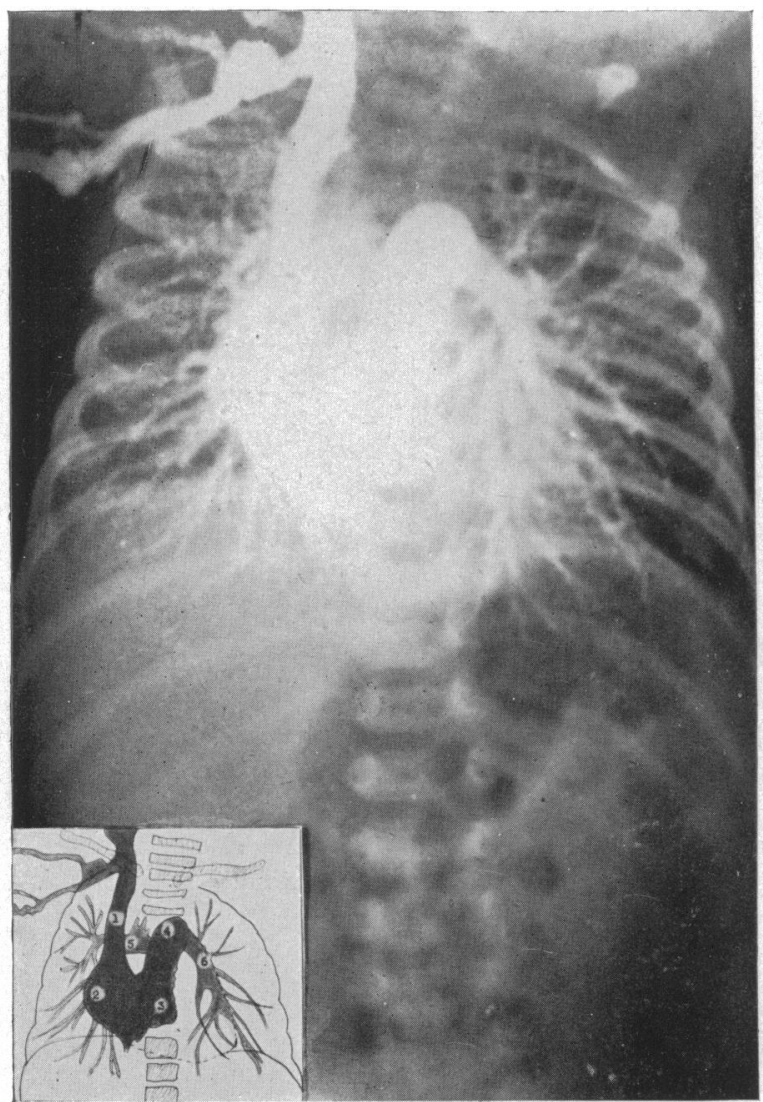

FIG. 3.-Dextro-angiocardiogram from infant with atelectasis of the right lung (see text).

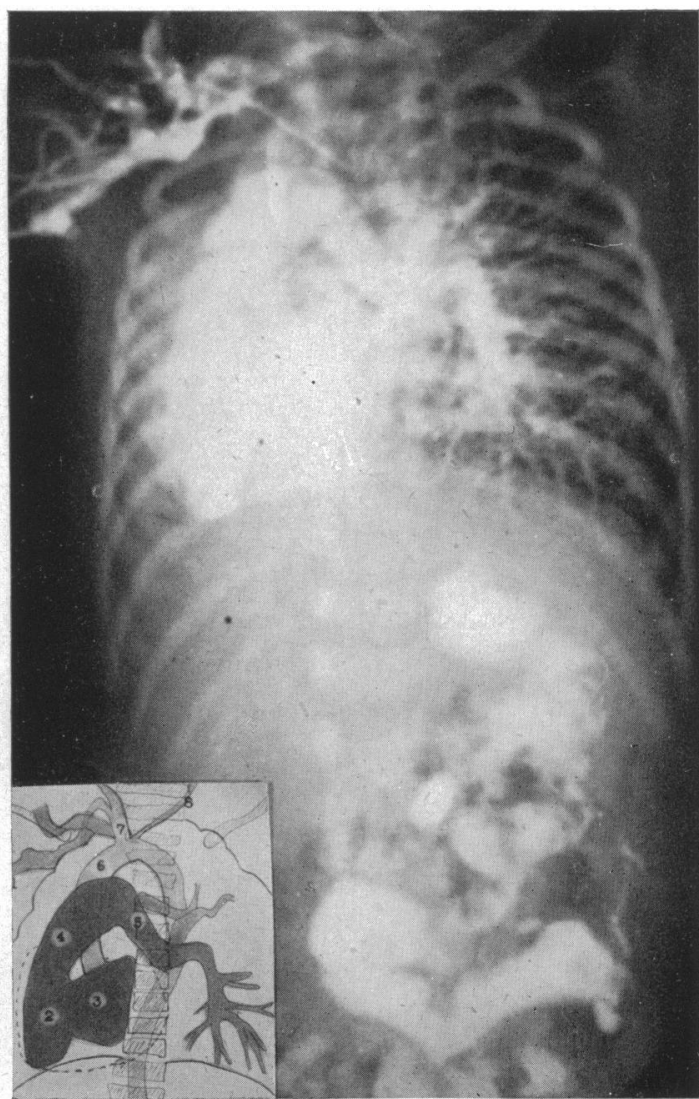

Fig. 4.-Dextro-angiocardiogram from an infant of one month with agenesis of the right lung (see text).

The angiocardiogram (Fig. 5) shows superior vena cava (1); right auricle (2); right ventricle (3); and the simultaneous filling of the aorta (10) and pulmonary artery. The latter emerges from the right ventricle through a very narrow pulmonary conus (4). The small size of the pulmonary valves (5) and both pulmonary arteries is noticeable. Number (6) shows the section of the right pulmonary artery and (13) shows the left. A strip connecting the lower border of the aortic arch (12) with the left pulmonary artery was considered to be the persistent ductus (11).

Based on these findings, we made a diagnosis of tetralogy of Fallot with extreme pulmonary stenosis and persistent ductus arteriosus, and to the closure of the latter we attributed the death of the patient a few weeks later.

Tetralogy of Fallot with Anomalous Distribution of the Vessels from the Aortic Arch

O.C.D., aged 4 years. Dyspnœa from birth; increasing cyanosis from the age of one year. Repeated attacks of dyspnœa and cyanosis with loss of consciousness. Not yet able to walk. Clubbing of the fingers and toes; loud, harsh systolic murmur, maximal in the second intercostal space to the left of the sternum. Electrocardiogram, marked right axis deviation. On fluoro-, scopy, the heart was seen to be somewhat enlarged; no prominence of the pulmonary conus; the aortic knob was on the left; the lung fields and pulmonary window were unusually clear. The diagnosis of tetralogy of Fallot was made.

The angiocardiogram confirmed the diagnosis and showed also the anomalous distribution of 
the vessels from the aortic arch. Fig. 6 shows superior vena cava (1); right cavities normally filled (2); some of the dye entering the left ventricle (6) through the interventricular septal defect. The simultaneous filling of a large aorta (4) and a very small pulmonary artery (3) is seen. Four branches come off the aorta: first the very big right carotid (7), the much smaller left carotid (8), the left sub-clavian artery (9), from which the vertebral emerges, and finally the right subclavian artery which originates in the posterior surface of the aortic arch (5), emerging as the last branch from it. The right subclavian runs between the trachea and the esophagus, and its pressure on the trachea probably contributed to his respiratory difficulty. The patient died and the necropsy confirmed these observations.

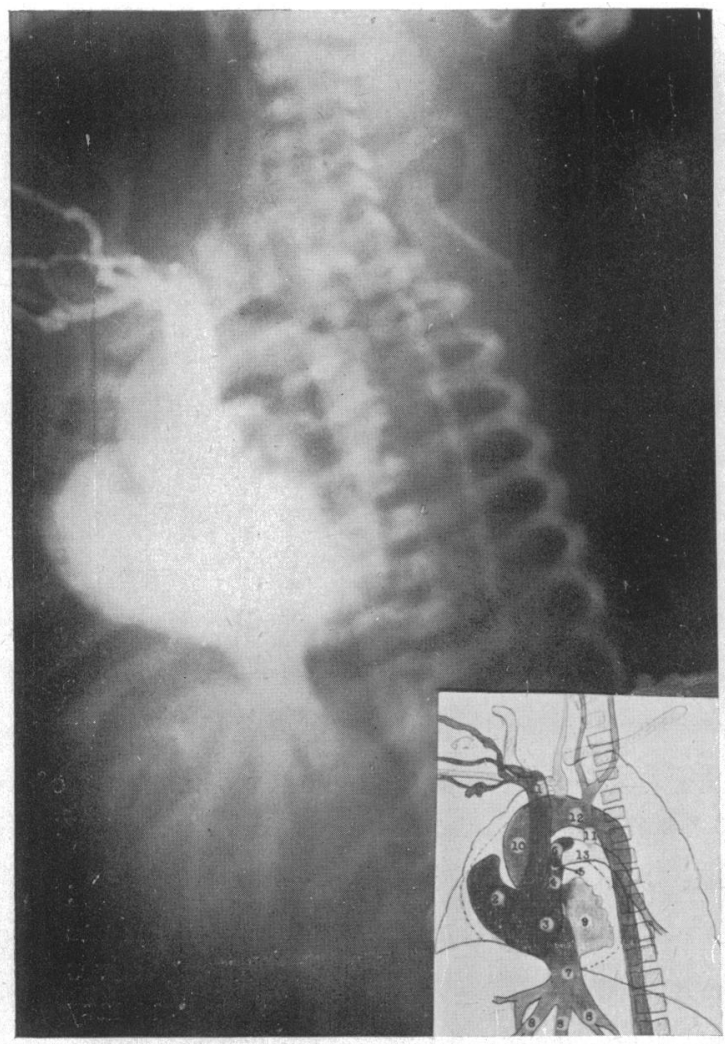

Fig. 5.-Dextro-angiocardiogram from a case of tetralogy of Fallot and persistent ductus arteriosus (see text).

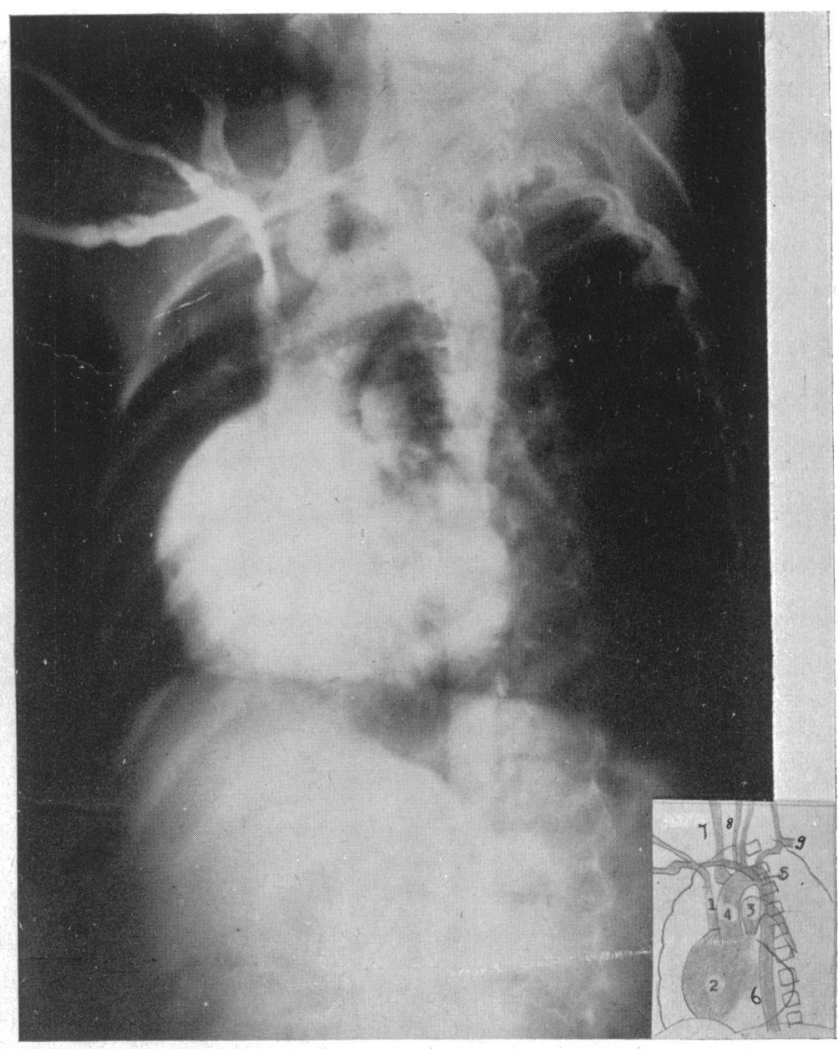

Fig. 6.-Dextro-angiocardiogram from a case of tetralogy of Fallot with anomalous distribution of the vessels from the aortic arch (see text).

\section{Persistent Ductus Arteriosus}

As angiocardiography is not the ideal procedure for the diagnosis of isolated persistent ductus arteriosus, Castellanos and Pereiras originated a method of direct visualization of the aorta, whereby the dye passes into the pulmonary artery through the ductus.

The direct angiocardiographic signs of persistent ductus arteriosus are: (a) the visualization of the ductus itself, very rarely seen in cases of isolated ductus, but more frequently seen when there are other malformations (Fig. 5 and 10), and (b) visualization of the infundibulum of the ductus - the aortic end of the ductus has an infundibular form which can be seen on the lævo-angiocardiogram. This was proved by Sussman and Grishman by attaching metal clips alongside the ductus during operation, and they described it as a "localized dilatation of the aorta on its anterior aspect just 
beyond the isthmus." In presenting a case, Keele (1948) showed that this convexity persisted after the ligation of the ductus, but that the prolonged or renewed filling of the pulmonary artery was no longer seen.

Their are three indirect signs. (a) Visualization of the aorta in the first films, as has been seen by Landivar and Martiarena (1947). The occurrence of this sign is very unusual unless there is also coarctation of the aorta in the infantile type, when the descending aorta is almost continuous with the ductus. (b) Renewed filling of the pulmonary artery in the lævo-angiocardiogram. This has more value when it is combined with the visualization of the infundibulum. (c) Dilatation of the main pulmonary artery and its left branch as well as its elevation, probably produced by the pulling of the ductus toward the aorta. This sign is found in many other instances in which the pulmonary artery is also large, such as auricular septal defect and congenital dilatation of the pulmonary artery with valvular stenosis.

J.L., aged 7 years. Heart murmur discovered during routine examination. The apex palpated in the fifth left intercostal space in the mid-clavicular line. Systolic thrill and murmur loudest at the second left intercostal space to the left of the sternum. Blood pressure 85/0. Fluoroscopic examination: heart slightly enlarged, prominent pulmonary conus with vigorous pulsation; increased pulmonary shadows and hilar dance. It seemed likely that this patient had a patent ductus, but the absence of a continuous murmur and the right axis deviation impelled us to take an angiocardiogram to make sure there was no pulmonary stenosis.

The dextro-angiocardiogram (Fig. 7) shows the superior vena cava (1); the right cavities (2-3) normally filled; and (4) the dilatation and elevation of the main pulmonary artery. This angiocardiogram excluded pulmonary stenosis and showed an indirect sign of patent ductus; these two facts caused us to advise the operation, which confirmed the diagnosis.

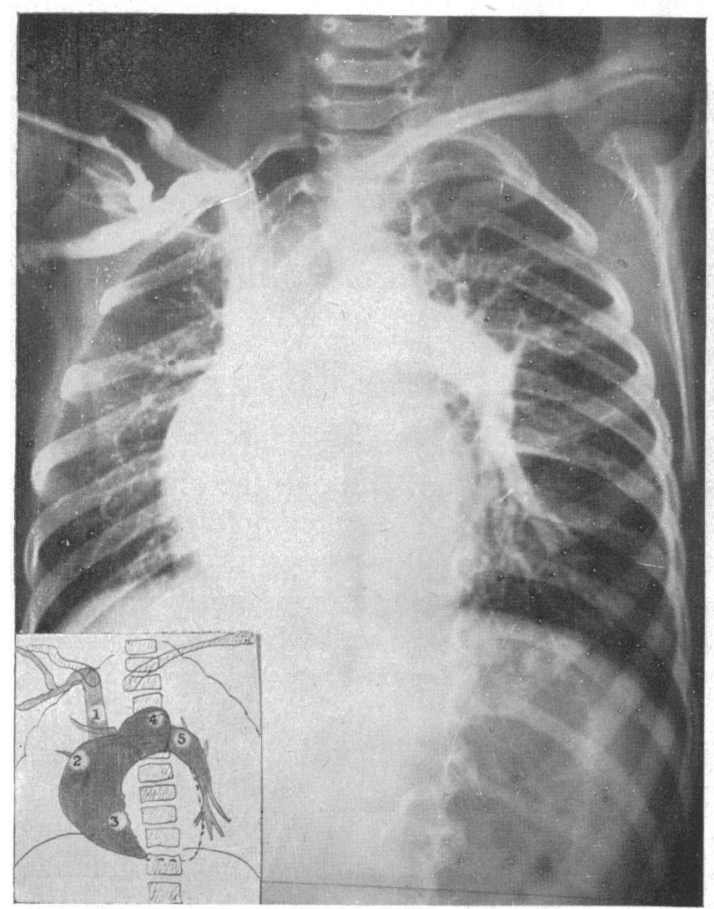

Fig. 7.-Dextro-angiocardiogram from a case of patent ductus arteriosus (see text).

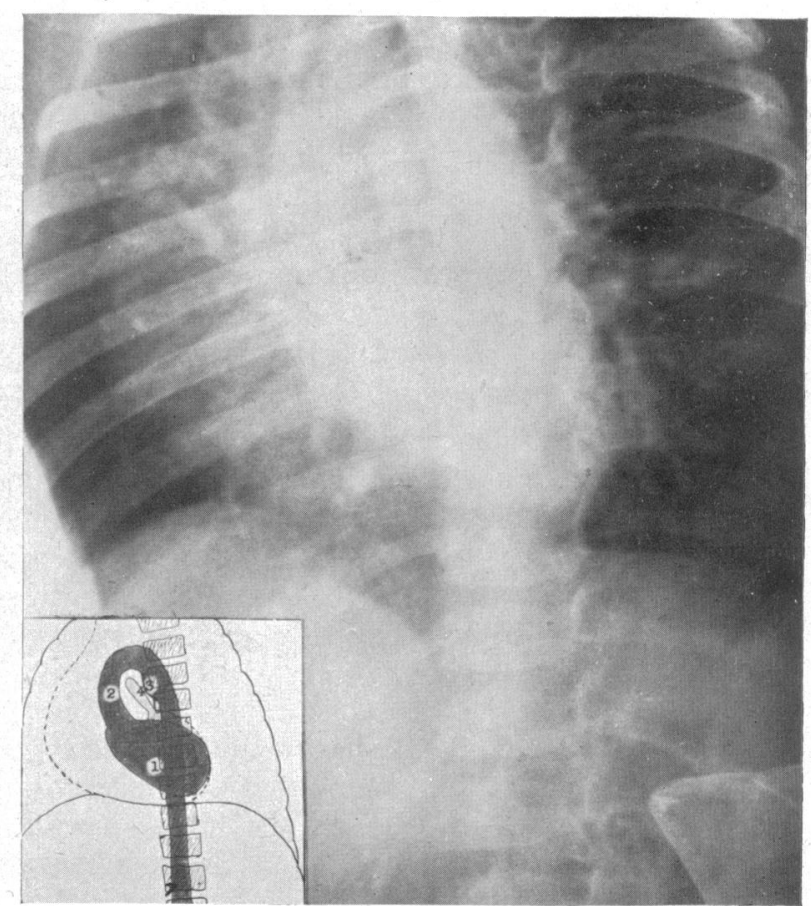

FIG. 8.-Lævo-angiocardiogram from a case of patent ductus arteriosus (see text) 
F.S., aged 3 years. Never had any symptoms: a continuous machinery murmur discovered accidentally. Electrocardiogram normal. Fluoroscopy showed heart somewhat enlarged, prominent pulmonary conus, and bilateral hilar dance.

The lævo-angiocardiogram (Fig. 8) shows the left cavities filled (1); the aorta (2); the prominence on the anterior aspect of the descending portion of the aortic arch (3), which corresponds to the infundibulum of the ductus; the refilling of the pulmonary artery (4)-which occupies the vascular window-is also seen, when the right ventricle has already emptied.

This patient was operated on and the murmur disappeared completely. A year later, a tenmonths-old brother of this child was diagnosed as having a patent ductus with cardiac insufficiency and was also operated on successfully.

\section{Infundibular Stenosis with Dilated Pulmonary Artery}

In these cases the dextro-angiocardiogram shows a characteristic picture which we have called "racket sign"; the stenosed portion corresponds to the handle, and the dilated pulmonary artery to the racket itself. Similar pictures have been shown by different authors (Keele, Dotter, Steinberg). This sign is clearly shown in the following case of a patient upon whom we considered operating before the angiocardiogram was taken. Therefore, even though the angiocardiogram may not be very valuable in the diagnosis of the patent ductus, we consider that it should be taken before recommending operation, whenever the clinical signs are not convincing or pronounced right axis deviation arouses the susplcion of pulmonary stenosis.

M.E.A., aged 8 years." Murmur accidentally discovered when the patient was three years of age; systolic thrill and harsh, loud systolic murmur over the second interspace to the left of the sternum. Blood pressure 100/70. Electrocardiogram, tendency to right axis deviation. X ray: no enlargement of heart, great prominence of the pulmonary conus with pulsation, and bilateral hilar dance.

The dextro-angiocardiogram (Fig. 9) shows a nice example of " racket sign." The dye is seen in the superior vena cava (1); the right auricle (2); the right ventricle (3); the stenosed infundibulum (4); and the dilated pulmonary artery (5), the two latter forming the racket. Also the dilated left (6) and right (7) branches of the pulmonary artery are seen. This same racket sign was seen on the angiocardiogram taken in the oblique position. We think that this child has pulmonary stenosis, proved by both angiocardiograms, and we presume she has also a patent ductus which would explain the hilar dance.

\section{Complete Transposition of the Great Vessels}

Although the clinical and radiological picture of this malformation has been beautifully described by Taussig, the angiocardiogram can be of great aid in the diagnosis. Although the only patient we have lost (whose death could be attributed to the angiocardiography) had a complete transposition of the great vessels, we do not believe the procedure to be especially dangerous in this malformation. In these cases, the dextro-angiocardiogram in the left anterior oblique position shows the early filling of the aorta which rises anteriorly from the right ventricle and whose arch has the form of a cane handle only slightly bent. The pulmonary artery is evident in the later films.

G.E., aged 5 days. Cyanosis and dyspnœa from birth with attacks of loss of consciousness, so frequent and lasting so long that they seriously endangered his life. Heart sounds normal; no murmurs. The X-ray showed the heart somewhat enlarged, absence of pulmonary conus, the vascular shadow at the base of the heart narrower in the anterior posterior than in the oblique position. Electrocardiogram, marked right axis deviation.

The dextro-angiocardiogram (Fig. 10) shows superior vena cava (1); right auricle (2); right ventricle (3); and a small amount of dye in the left auricle (9). From the right ventricle, the aorta 


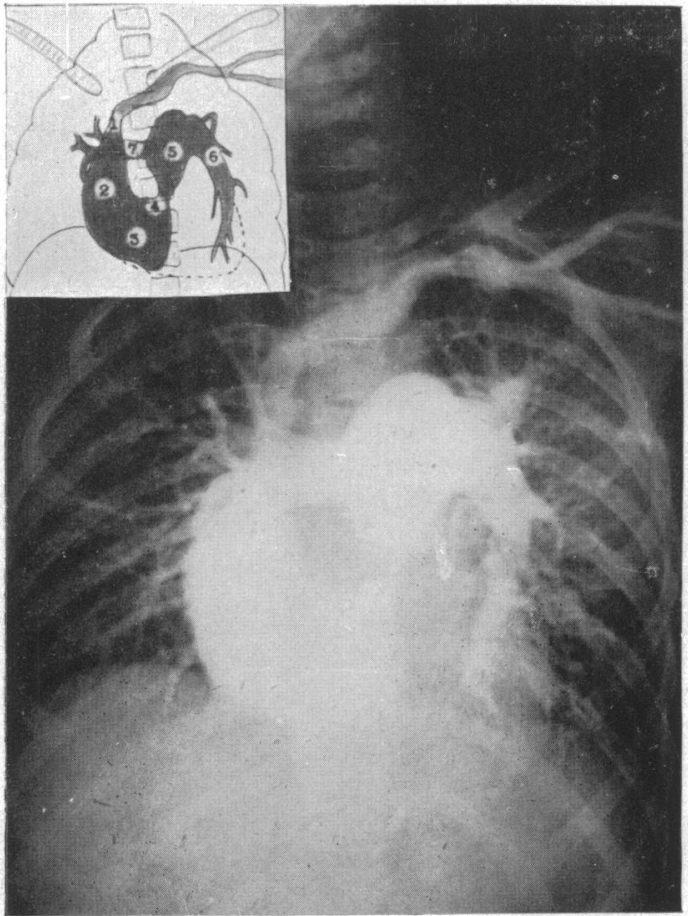

Fig. 9.-Dextro-angiocardiogram from a case of infundibular pulmonary stenosis with dilated pulmonary artery (see text).

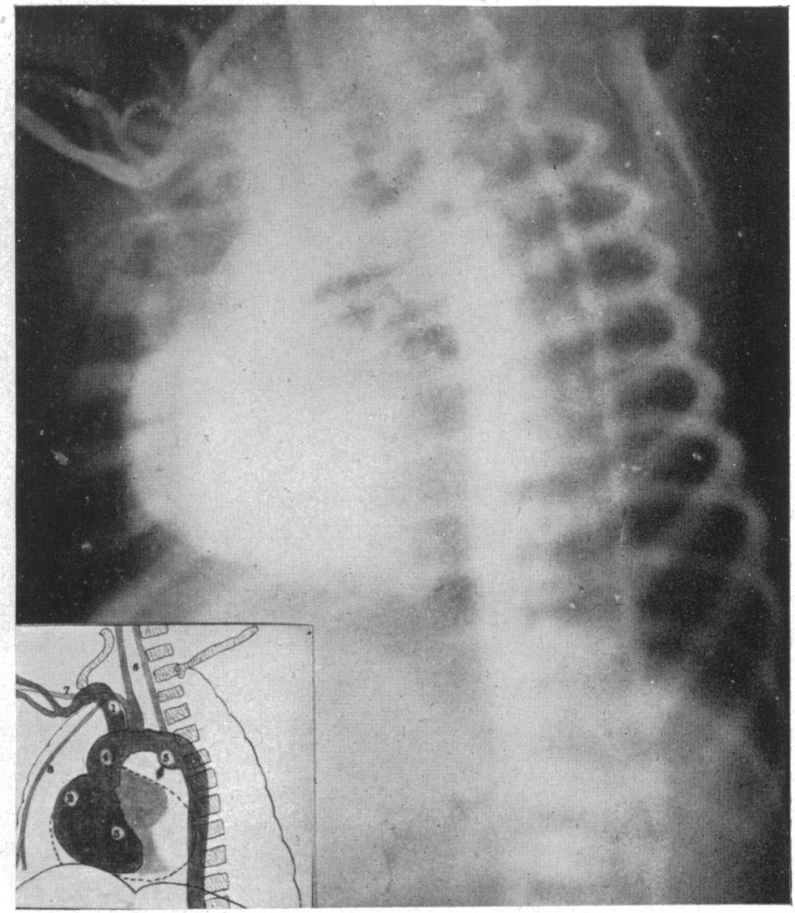

Fig. 10.-Dextro-angiocardiogram from a case of complete transposition of the great vessels (see text).

is seen to arise, its arch forming an open curve. The bulge (5) was thought to be the infundibulum of a patent ductus arteriosus and the little strip arising from it to be the ductus itself. From the aortic arch the main vessels arise and several of its branches are seen. In the later films the left branch of the pulmonary artery is seen.

At the time we saw the patient, and based on the angiocardiogram, we incorrectly diagnosed the case as a tetralogy of Fallot. Now, having a better knowledge of the angiocardiographic picture of transposition of the great vessels, it seems unlikely that we would make the same mistake again. The necropsy revealed a complete transposition of the great vessels with an auricular septal defect and a patent ductus arteriosus.

\section{Coarctation of the Aorta}

Although the direct visualization of the aorta by means of the injection of the dye through a catheter introduced through a humeral or carotid artery is a better method for the study of this malformation, the angiocardiogram may be helpful in determining the site of the coarctation as well as to show the pathways of the collateral circulation.

J.C.R.*, aged 5 years. From the age of 4, complained of pains in both legs. At the age of 6 found to have a murmur and treated as rheumatic fever. On examination, he was found to have a rough, loud systolic murmur over the entire præcordium and a short, low-pitched diastolic murmur at the apex. No femoral pulse was palpable. Blood pressure, 180/130 in the arms. Electrocardiogram, tendency to right axis deviation.

\footnotetext{
* This case was reported before the Sociedad Argentina de Cardiologia.
} 
The lævo-angiocardiogram (Fig. 11) shows the left cavities filled (1); and the aorta (2) arising from the left ventricle with its branches. After the emergence of the left subclavian, the shadow cast by the aortic arch is suddenly interrupted as is shown by the arrow (6). The patient was operated on, and a complete occlusion of the aorta was found $1 \mathrm{~cm}$. under the place where the left subclavian arose.

\section{Taussig's Syndrome}

Taussig and Bing (1949) described the clinical picture of the complete transposition of the aorta and the over-riding of the pulmonary artery. The case presented here was diagnosed as such a malformation, the diagnosis being sustained by the angiocardiogram.

A. del V., aged 8 years. Cyanosis from early in life; squatting when tired; harsh, loud systolic murmur over entire præcordium. X-rays showed heart not enlarged, a prominent pulmonary conus, and a bilateral hilar dance.

The dextro-angiocardiogram (Fig. 12) shows the normal filling of the right cavities (2-3) through the superior vena cava (1); the aorta (5) arises entirely from the right ventricle and its arch forms an open curve, as is usually seen when this vessel is transposed. The pulmonary artery (4) of normal size is seen to arise behind the aorta and probably over-rides the septum. A small amount of dye has entered the left ventricle through the ventricular septal defect.

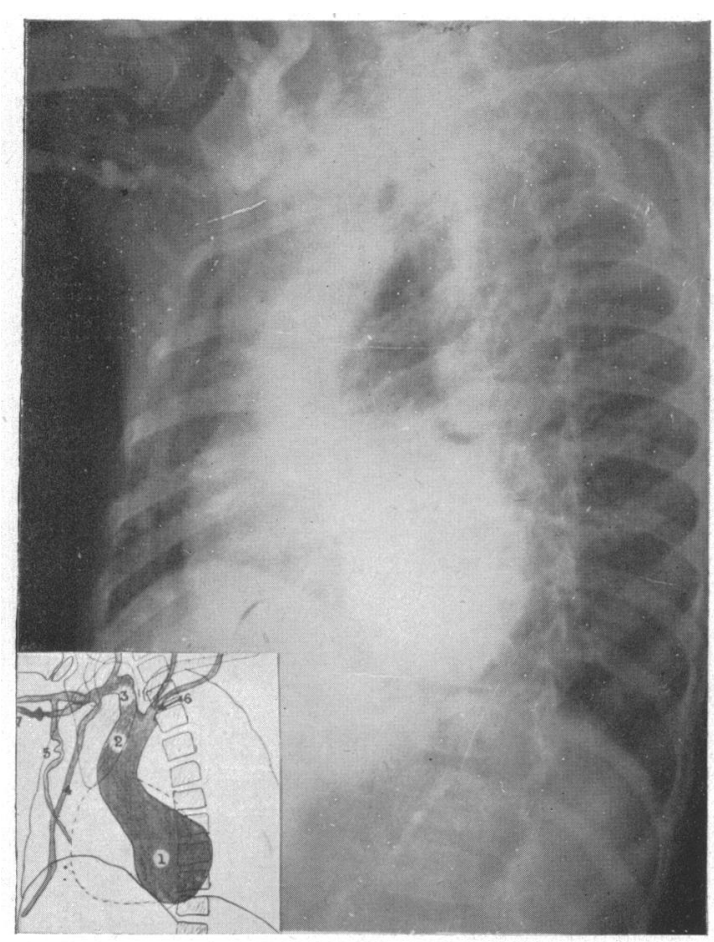

FIG. 11.-Lævo-angiocardiogram from a case of coarctation of the aorta (see text).

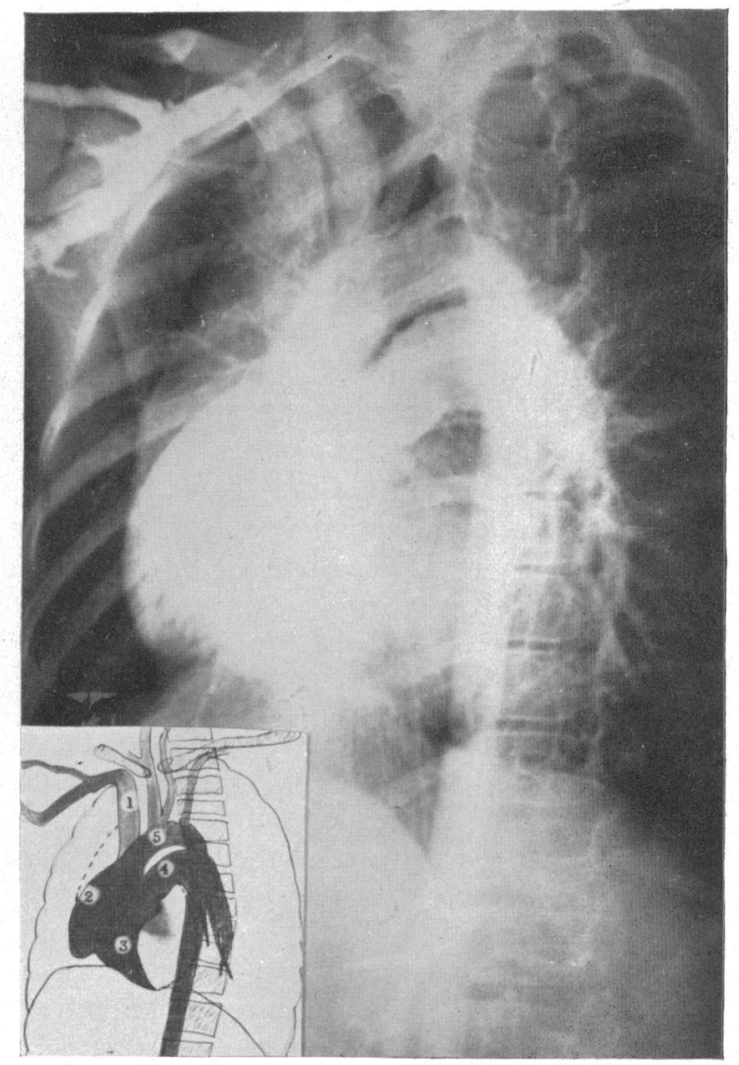

FIG. 12.-Dextro-angiocardiogram from a case of Taussig's syndrome (see text). 


\section{Mediastinal Tumour (Hydatic Cyst)}

T.B., aged 9 years. Admitted to hospital with diphtheria. On examination, slight generalized cyanosis and moderate clubbing of the fingers; a harsh, loud systolic murmur at the left base. Electrocardiogram, right axis deviation. X ray (Fig. 13) showed heart of normal size and a great prominence in the region of the pulmonary conus, which, on fluoroscopy was seen to pulsate vigorously. The possibility of an hydatic cyst was considered, but the Ghedini reaction was negative and the Casoni reaction only very slightly positive.

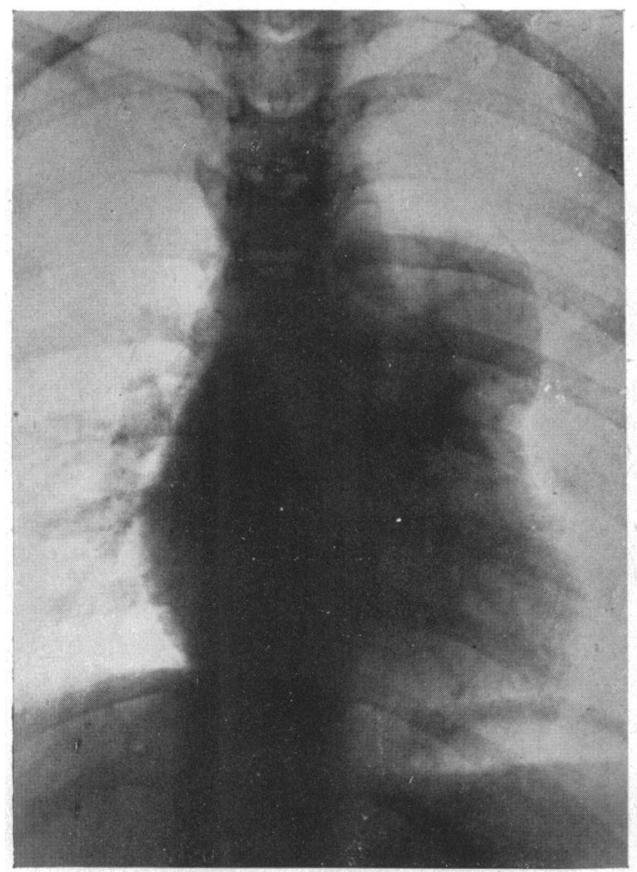

Fig. 13.-Teleradiogram from a case of mediastinal tumour (hydatic cyst).

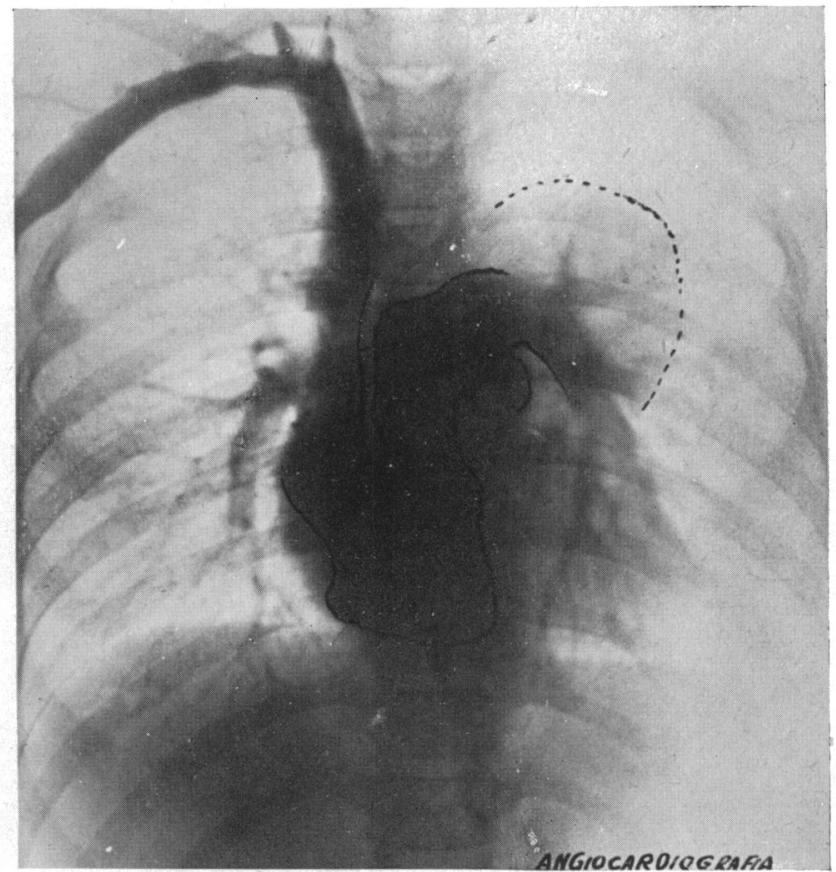

FIG. 14.-Dextro-angiocardiogram from the same case of mediastinal tumour.

Considering the possibility of a congenital malformation of the heart, an angiocardiogram (Fig. 14) was taken, showing the complete independence of the tumor from the pulmonary artery. In consequence, the pulsations we saw on fluoroscopy were transmitted from the pulmonary artery. The patient was operated on, with the diagnosis of congenital cyst. Much to our surprise an hydatic cyst was discovered and was successfully removed. After the operation, the cyanosis, the clubbing, and even the murmur disappeared completely. This suggests that she really had a pulmonary stenosis produced by the compression of the cyst on the pulmonary artery.

\section{SUMMARY AND CONCLUSIONS}

We practice angiocardiography using iodoxil as the contrast medium, without exposing the vein and without general anæsthesia.

Here we present a series of angiocardiograms to demonstrate its value in:

(a) the study of the radiological topography of the cardiovascular silhouette,

(b) the diagnosis of pulmonary atelectasis and pulmonary agenesis,

(c) the diagnosis of the different congenital malformations of the heart, and

(d) the differential diagnosis of mediastinal tumours. 
We consider angiocardiography the procedure that gives the most valuable information in the diagnosis of congenital heart disease during infancy.

\section{REFERENCES}

Ameuille, Ronneauz, Hinault, Desgrez, and Lemoine (1936). Bull. Mem. Soc. Med. Hôp., Paris, 16, 729.

Carson, M. J., Burford, T. H., Scott, W. G., and Goodfriend, J. (1948). J. Ped., 33, 525.

Castellanos, A., Pereiras, R., and Garcia, A. (1937). Arch. Soc. Est. Clin. Habana, 31, 523.

Chavez, I., Celis, A., and Dorbecker, M. (1947). Amer. Heart J., 33, 560.

Conte, E., and Costa, A. (1933). La Presse Med., 1, 767.

Dotter, C. T., and Steinberg, I. (1949). Ann. intern. Med., 30, 1104.

Forssmann, W. (1929). Klin. Wschr., 2, 2805.

Keele, K. D. Personal communication.

- (1948). Brit. J. Radiol., 21, 380.

Kreutzer, R. (1948). Arch. Arg. Ped., 29, 309.

- (1947). Biblioteca de Terapeutica de Cardini y Beretervide; El Ateneo, Buenos Aires.

(1949). Biblioteca de Terapeutica de Cardini y Beretervide, vol. 4, parte 3, p. 352; El Ateneo, Buenos Aires. Pelliza, J. M., and Calisti, S. (1944). Arch. Arg. Ped., 22, 32.

Landivar, A. F., and Martiarena, L. (1947). Bol. Trab. Acad. Cir., 31, 320 and 339.

Malenchini, M., Roca, J., and Rua, L. (1949). El Dia Medico, 21, 1091.

Moniz, E., Carvalho, L. de, and Lima, A. (1931). La Presse Med., 2, 996.

Pennington, S. Personal communication.

Ravina, A., Sourire, A., and Benzaquen, L. (1937). La Presse Med., 1, 287.

Reboult H., and Racine M. (1933). Ibid., 41, 763.

Robb, G. P., and Steinberg, I. (1938). J. Clin. Invest., 17, 507.

Segura, A. S., Lavisse, J., and Stiefel, O. M. (1945). Arch. Arg. Ped., 24, 183.

Spangenberg, J. J., Munist, L., Ardaiz, A., and Lemos Garcia, M. (1942). Prensa Medica Arg., $29,327$.

Sussman, M. L., and Grishman, A. (1947). Advances in Internal Med., vol. 2, p. 102; Intersciences Pub. Inc., N.Y.

Taussig, H. B. (1947). Congenital Malformations of the Heart, Commonwealth Fund, New York.

- and Bing, R. J. (1949). Amer. Heart J., 37, 551.

Taylor, H. K., and McGovern, T. (1943). J. Amer. med. Ass., 121, 1270.

Thoyer-Rozat, P., and Piquet, J. (1949). J. Rad. d'Elect., 30, 3. 